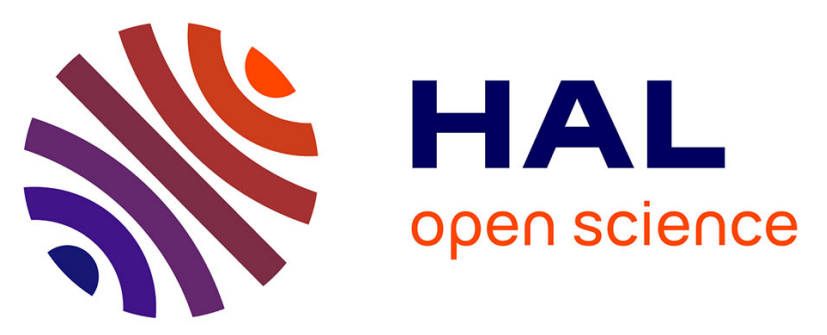

\title{
ANTIMICROBIAL PEPTIDES EXPRESSION BY OCULAR SURFACE CELLS IN RESPONSE TO ACANTHAMOEBA CASTELLANII: AN IN VITRO STUDY
}

Ahmad Muneer Otri, Imran Mohammed, Asiya Abedin, Zhiyi Cao, Andrew Hopkinson, Noorjahan Panjwani, Harminder Singh Dua

\section{To cite this version:}

Ahmad Muneer Otri, Imran Mohammed, Asiya Abedin, Zhiyi Cao, Andrew Hopkinson, et al.. ANTIMICROBIAL PEPTIDES EXPRESSION BY OCULAR SURFACE CELLS IN RESPONSE TO ACANTHAMOEBA CASTELLANII: AN IN VITRO STUDY. British Journal of Ophthalmology, 2010, 94 (11), pp.1523. 10.1136/bjo.2009.178236 . hal-00561326

\section{HAL Id: hal-00561326 https://hal.science/hal-00561326}

Submitted on 1 Feb 2011

HAL is a multi-disciplinary open access archive for the deposit and dissemination of scientific research documents, whether they are published or not. The documents may come from teaching and research institutions in France or abroad, or from public or private research centers.
L'archive ouverte pluridisciplinaire HAL, est destinée au dépôt et à la diffusion de documents scientifiques de niveau recherche, publiés ou non, émanant des établissements d'enseignement et de recherche français ou étrangers, des laboratoires publics ou privés. 


\section{Antimicrobial Peptides Expression By Ocular Surface Cells In Response To Acanthamoeba Castellanii: An In Vitro Study}

Authors: ${ }^{1}$ Ahmad Muneer Otri, ${ }^{1}$ Imran Mohammed, ${ }^{1}$ Asiya Abedin, ${ }^{2}$ Zhiyi Cao, ${ }^{1}$ Andrew Hopkinson, ${ }^{2}$ Noorjahan Panjwani, ${ }^{1}$ Harminder S Dua.

Affiliation: 1. Division of ophthalmology and visual sciences, University of Nottingham, England and 2. New England Eye Centre, Tufts University School of Medicine, Boston, MA, USA

Word count: Abstract: 201. Manuscript: 2482 words

Key words: Antimicrobial peptides, Acanthamoeba castellani, human corneal limbal epithelial cells, gene expression

Financial Disclosure: None of the authors have any proprietary/financial interest to disclose.

\section{Corresponding Author}

Harminder S Dua

Division of Ophthalmology and Visual Sciences

B Floor, Eye ENT Centre

Queens Medical Centre, Nottingham University Hospitals NHS Trust

Derby Road, Nottingham. NG7 2UH

England. UK.

Harminder.dua@nottingham.ac.uk

Telephone +441159709796

Fax +441159709963 


\section{Abstract}

Aims: Antimicrobial peptides (AMPs) are natural effectors of the innate immune response. Much work has been done to study their response and effects on bacterial and viral infection. Little if any information is available in relation to protozoal infections. Our aim was to comprehensively study the gene expression of the ocular AMPs in human corneal limbal epithelial cells (HCLE) stimulated with Acanthamoeba castellanii $(A C)$.

Methods: Human corneal limbal epithelial cells were exposed to $A C$ at different time points, up to 9 hours, the genomic profile of the AMPs were analysed at these time point using real time PCR. HCLE cells not infected with AC were used as controls.

Results: Seven of the 8 studied AMPs showed statistically significant upregulation in gene expression. Human beta Defensin 3 (hBD3) showed a very significant 10 fold upregulation in the exposed cells and Ribonuclease-7 (RNase-7) showed a very early and consistent increase. Human beta Defensin 1 (hBD1) was the only downregulated AMP.

Conclusions: The study data suggests a possible role of the AMPs in combating the amoebic infection at the ocular surface. Using AMPs singly or in combination is a promising avenue for further exploration in the treatment of the sight threatening Acanthamoeba keratitis. 


\section{Introduction}

The ocular surface comprises of cornea, conjunctiva, and tear film. Like other mucosal surfaces, it is in direct contact with the environment and exposed to environmental pathogens such as bacteria, viruses, fungi, and protozoa. It also maintains a population of commensal organisms, which have the potential to cause opportunistic disease. To combat these threats, the ocular surface has developed innate and adaptive immune mechanisms.[1] One important component of the innate response is the repertoire of antimicrobial peptides (AMPs). AMPs are ubiquitous natural effectors of the host defence system and are conserved across the plant and animal kingdom with broad spectrum microbicidal activity and cell signalling functions. They can be considered to represent the eukaryotic analogues of antibiotics.[2, 3]

At the ocular surface the epithelial cells and neutrophils are a major source of AMPs which include beta Defensins (BD) 1 to 4 \& 109, Liver expressed antimicrobial peptide 1 (LEAP) 1 (also known as Hepcidin) and LEAP 2, Cathelicidin (LL37) [4], and Ribonuclease-7 (RNase-7) (unpublished observation). Acanthamoeba is a ubiquitous free-living genus of amoeba that can survive in diverse conditions and has been isolated from tap water, seawater, soil, dust and air. The life cycle of Acanthamoeba has two stages: a replicative trophozoite stage that under adverse conditions such as extreme temperature, starvation, or osmolarity changes can develop into a dormant cyst stage. [5, 6]

Acanthamoeba is notorious as a cause of serious corneal infection particularly amongst wearers of soft contact lenses. The infection is sporadic but two outbreaks have been recently reported in Chicago and Singapore. $[7,8]$ The mechanism by 
which this infection occurs is directly related to the ability of Acanthamoeba trophozoites to adhere to mannose glycoproteins on the corneal epithelium via the amoeba's mannose-binding receptor.[9-11] This binding induces production of a cytolytic factor, mannose-induced protein (MIP133), by the Acanthamoeba.[12] Subsequently, a number of matrix metalloproteases are activated, killing corneal epithelial cells, and penetrating the cornea by dissolution of the basement membrane and the underlying collagen of the Bowman's zone and stroma. [11, 13, 14]

Although there are several studies on the gene expression of AMPs in corneal epithelial cells challenged with microbial stimuli, there is no work on AMPs expression by any human cell type in response to Acanthamoeba. In this study we characterized the profile of AMPs gene expression by a human corneal limbal epithelial cells exposed to live Acanthamoeba castellanii.

\section{Methods}

\section{Human cell culture}

Telomerase reverse transcriptase-immortalized human corneal limbal epithelial cells (HCLE) were used in this study. This cell line has been shown to be very similar to the native corneal epithelium in relation to cornea specific keratin and mucin expression and other parameters. [15-17] According to previously described protocols [15], HCLE were maintained in keratinocyte serum-free media (K-SFM; Invitrogen, Carlsbad, CA) supplemented with $0.2 \mathrm{ng} / \mathrm{ml}$ epidermal growth factor (EGF), $25 \mu \mathrm{g} / \mathrm{ml}$ bovine pituitary extract (BPE) and $0.4 \mathrm{mM} \mathrm{CaCl} 2$ at $37{ }^{\circ} \mathrm{C}$ in a $5 \%$ CO2 humidified incubator. The HCLE were subcultured in 6-well cell culture plates $\left(9.5 \mathrm{~cm}^{2}\right.$; BD, Franklin Lakes, $\left.\mathrm{NJ}\right)$ until confluency was reached and then starved 
overnight in growth supplement and BPE free media before exposure to Acanthamoeba.

\section{Isolation and culture of Acanthamoeba castellanii trophozoites}

Acanthamoeba castellanii (AC) trophozoites: An Acanthamoeba strain derived from an infected human cornea (MEEI 0184; $A$. Castellanii, genotype T4) was used throughout this study. The parasites were axenically cultured in a proteose peptoneyeast extract-glucose (PYG) medium prior to the exposure/stimulation studies.[18]

\section{Acanthamoeba exposure/stimulation of HCLE}

The final density of the Acanthamoeba used was $2 \times 10^{5}$ amoebae/ ml. $1.5 \mathrm{ml}$ of amoebae suspension was used for each $60 \mathrm{~mm}$ dish. Amoebae from PYG media were washed and suspended in the following media: $[1 \mathrm{ml}$ of Non-essential amino acid, $10 \mathrm{ml}$ of $4 \% \mathrm{BSA}$ and $89 \mathrm{ml}$ of Eagle's minimal essential medium, (EMEM) with L-Glutamine] prior to stimulating HCLE cells. The confluent HCLE cells were incubated with $A$. castellanii trophozoites and samples were collected at 1, 3, 6 and 9 hours. Control samples were obtained from non stimulated HCLE. At each time point, the culture media was removed and $700 \mu$ of RLT buffer (Qiagen) was added $t$ each well for 15 minutes until the cells were fully solubilised and the lysate was collected and stored at $-80 \mathrm{C}$. Additionally, the suspension of Acanthamoeba culture (without cells) was collected separately and spun down for 2 mins at 16,000 rpm. $700 \mu \mathrm{l}$ of RLT buffer (Qiagen) was added and the samples were kept at $-80^{\circ} \mathrm{C}$ for further analysis. All tests were done in triplicate and each of the triplicate set of tests was on cells of the same passage. The morphology of the immortalized cells used in 
the current study was very similar to that of the primary cultures of human corneal epithelium.

\section{Isolation of total RNA and cDNA synthesis.}

Total RNA was extracted from RLT lysate using the RNeasy Mini kit, (according to manufacturer's instructions; Qiagen). Reverse Transcription into cDNA of $4 \mu \mathrm{g}$ of template RNA from cultured cells was carried out according to the manufacturer's instructions (Quantitect Reverse Transcription kit, Qiagen).

\section{Quantitative real-time PCR (qPCR)}

QPCR analysis was performed to measure the relative gene expression of the following AMPs: beta Defensins (hBD1, hBD2, hBD3, and BDEF109), LL37, LEAP1, 2 and RNase-7 mRNA

Pre-optimised Real-time qPCR reactions were run on a 96-well plate (Applied Biosystems) in the Mx3005p real-time PCR system (Stratagene, Agilent Technologies, UK). The data obtained from the machine were further analysed to calculate the relative gene expression of AMPs mRNA levels Taqman assays (Applied Biosystems, Europe) were used for all the AMPs genes and the endogenous control [Hypoxanthine-guanine phosphoribosyltransferase (HPRT)].

The details of genes and Taqman IDs are given in table 1. 
Table1- Details of genes and accession numbers used in the study. (Applied Biosystems, Europe)

\begin{tabular}{|c|c|c|}
\hline Gene Symbol & Taqman assay ID & Accession number \\
\hline HPRT & 4333768F & NM_000194.1 \\
\hline DEFB1/Hs00174765_m1 & Defensin, beta1/HBD1 & NM_005218.3 \\
\hline DEFB4/Hs00823638_m1 & Defensin,beta4/HBD2 & NM_004942.2 \\
\hline DEFB103A/Hs00218678_m1 & Defensin,beta103A/HBD3 & NM_018661.2 \\
\hline CAMP/Hs00189038_m1 & Cathelicidin AMP & NM_004345.3 \\
\hline HAMP/Hs00221783_m1 & Hepcidin AMP (LEAP 1) & NM_021175.2 \\
\hline LEAP2/Hs00364834_m1 & Liver expressed AMP2 & NM_052971.2 \\
\hline Hs00261482_m1 & RNase7 & NM_032572.3 \\
\hline Hs02760065_g1 & DEF109 & NM_001037380 \\
\hline
\end{tabular}

\section{Statistical analysis}

The qPCR data was statistically analyzed on the SPSS 16.0 ver (IBM, Chicago, IL) software with significance set at $P<0.05$. Using the Student's $t$-test, the mRNA expression in treated samples with those obtained in untreated controls was compared. All data was represented as mean and standard error of two independent experiment performed in triplicate. 


\section{Results}

AMPs expression in Acanthamoeba-exposed HCLE showed a statistically significant upregulation in 7 of the 8 studied AMPs. hBD1 was the only AMP which showed variable decrease in the gene expression. It showed reduced expression at all time points with the downregulation at the 6 hour time point $(0.6$ fold) reaching statistical significance $(P=0.038$, Figure $1-A)$.

hBD2 gene expression_increased with time with a dramatic and significant four folds increase at 9 hours $(P=0.036$, Figure $1-B)$.

hBD3 gene expression showed a significant upregulation at 3,6 , and 9 hours ( 7 folds, 7.5 folds, and 10 folds, respectively $)(P=0.044, P=0.00050, P=0.017$ respectively, Figure $1-\mathrm{C})$.

DEF109 gene showed a trend towards decreased expression for the first 6 hours but this did not reach statistical significance. It increased and reached a significantly higher level at the 9 hour time point ( 1.5 fold, $p=0.002$, Figure $1-\mathrm{D})$

LL37 gene expression varied slightly over the time course with a slight but significant increase at the 9 hours time point $(p=0.003$, Figure $1-E)$

LEAP1 gene expression was variable at the earlier time points but was significantly unregulated at 9 hours ( 5 folds increase, $p=0.001$, figure $1-F$ ). 
LEAP2 gene expression showed a significant down regulation at the 3 hours time point $(p=0.002$, Figure $1 \mathrm{~g})$ and then a statistically significant up-regulation at 6 and 9 hours ( 2 and 3.5 folds increase, $p=0.033, p=0.0001$ respectively, Figure $1-G$ ). RNase 7 gene expression showed significant upregulation at all time points from 1 to 9 hours $(p=0.04, p=0.03, p=0.003, p=0.006$; Figure $1 \mathrm{~h})$, with the highest expression (3.5 fold) at 9 hours. (Figure $1-\mathrm{H}$ )

Quantitative RT-PCR of cDNA obtained from lysate of $A$ castellani organisms that were maintained in culture for 24 hours did not show any AMP expression.

\section{Discussion}

AMPs are a component of the innate immune defence and as such respond early to any external challenge with microbes. These responses are known to occur within a few hours of the microbe interacting mainly with the toll like receptors of the surface cells.[19] Hence we decided to study the responses in the early time points following infection. We did extend the time course study to 24 hours but most host cells had lysed and meaningful information could not be obtained (data is not presented).

The upregulation of AMPs and other epithelial-derived components of innate immunity, e.g. inflammatory cytokines, is thought to be a key component of an effective defence against infection at the ocular surface.[20] AMPs contribute to the host defence by direct action on microbes and also by augmenting other defence pathways via host cell stimulation.[21] It is also demonstrated that AMPs can work synergistically with more than one AMP working together in mounting a host defence response. Two or more AMPs acting together may have equally potent antimicrobial 
effects at smaller concentrations. This strategy may be a way of overcoming undesirable side effects of AMPs on host cells seen at higher concentrations.[22]

The anti-amoebic effect of specific AMP (Magainins) has been previously established $[23,24]$. Schuster et al showed that Magainin peptide in combination with silver nitrate and/or other antimicrobial agents have in vitro activity against Aanthamoeba trophozoites and cysts.[23] Sacramento et al have recently shown increased permeabilisation of $A$. castellanii with peptides of $\alpha$-helical or $\beta$-sheeted AMPs. Some of these peptides were hydrolysed by Acanthamoeba culture supernatants suggesting enzymatic digestion. They suggested use of more specific peptides that are resistant to proteolysis produced by the organism or the combined use of the AMPs with specific protease inhibitors.[25] Our study is therefore of relevance as the potential to treat Acanthamoeba corneal infections with AMPs has been demonstrated.

Our in vitro study demonstrated statistically significant upregulation of 7 AMPs out of 8 studied following interaction of epithelial cells with A. castellanii.

Human hBD3 has independent broad spectrum in vitro antimicrobial activity against gram negative bacteria, gram negative bacteria, fungi and some viruses. This action is least affected by salt found in tear film on the ocular surface compared with the other AMPs.[21, 26] In this study hBD3 was the most significant, almost doubling the gene expression at three hours and showing a ten fold increase at 9 hours. This AMP had the maximum increased expression of all AMPs studied and the increase 
also started at an early time point. This was followed by LEAP1, hBD2 and RNAse-7. At the 9 hour time point hBD3 expression was two and a half times more than hBD2 and RNAse-7 and two times that of LEAP1. This upregulation could suggest a specific anti-amoebic role of the hBD3 gene on the ocular surface.

LEAP1 (Hepcidin) showed significant up regulation only at the 9 hour time point. This AMP was initially noted for its antimicrobial effects and has been linked to iron metabolism.[27] Its expression was predominantly detected in the liver and to a much lower extent, in the heart. It is now recognized for iron homeostasis and through this mechanism may contribute to the innate immunity by restricting iron availability to microbes [28] like lactoferrin which is a known constituent of tears.[29] LEAP1 has demonstrable in vitro antibacterial activity against Gram-positive and Gram-negative bacteria as well as the yeasts. [30]

Like LEAP1, hBD2 also showed up-regulation of the gene expression at 9 hours. This AMP's expression is upregulated by proinflammatory cytokines such as TNF- $\alpha$ and IL -1ß.[31] AT the ocular surface, hBD2 is known to be inducible in response to Gram positive and Gram negative bacteria.[22] It has potent antimicrobial effect against Pseudomonas aeruginosa and Staphylococcus. aureus.[21]

Human hBD1 is constitutively expressed on the ocular surface and its expression does not change much with bacterial infection.[21, 32] In this study, with Acanthamoeba too, it showed downregulation at all time points. This could be 
explained by the non-inducible nature of this AMP on the ocular surface [22] which could indicate a limited antimicrobial role of the hBD1 in infectious diseases.

LL37 has good activity against both Gram negative and Gram positive bacteria. Additionally, it has antiviral effects when tested in vitro.[21, 33] However, in response to Acanthamoeba, its upregulation was not as much as has been reported with bacteria and may represent a differential response to protozoan infection.

The expression of DEFB109 showed significant up-regulation in in vitro samples at 9 hours with variable downregulation at early stages. We have previously shown down-regulation of DEFB109 gene expression in patients with Acanthamoeba keratitis.[32] This downregulation could be related to the fact that all the patients with Acanthamoeba keratitis were contact lens wearers. Interaction of hydrophilic contact lenses with epithelial cells in vitro has demonstrated a downregulation in expression of hBD2 following exposure to Pseudomonas aureginosa. [34] Unlike in samples taken from patients' eyes, in vitro exposure to Acanthamoeba showed upregulation of DEFB109 suggesting that expression of this AMP is susceptible to external influences.

LEAP2 showed early downregulation at 3 hours then up-regulation at 6 and 9 hours, though comparatively less than other AMPs. Although, chicken Liver Expressed Antimicrobial Peptide-2 (cLEAP-2) is known to have killing activities against Salmonella spp and Gram positive bacteria, [35] It is well documented that human LEAP-2 is not microbicidal peptide. The secondary structure of this AMP has a negative effect on its antibacterial activity in humans.[36] 
RNase-7 exhibits broad spectrum antimicrobial activity in vitro against several potentially pathogens like Gram-positive bacteria, Gram-negative bacteria and the yeast Candida albicans. Furthermore, RNase-7 shows extremely high activity against vancomycin-resistant Enterococcus faecium. [37] In our study, RNase-7 gene expression revealed remarkable early upregulation in HCLE in response to $A$. castellani. This continued to increase gradually. This finding could suggest a possible role of this highly cationic AMP in the anti amoeba activity.

There was no AMPs gene expression in samples taken from lysate of Acanthamoeba alone which confirmed the specificity of the TaqMan probes against the human AMPs genes in the HCLE.

This study provides a comprehensive profile of the ocular surface AMP gene expression in response to $A$. castellani infection. The profile differs from that seen following bacterial infection and illustrates the differential expression in response to different organisms. It provides the foundation upon which further studies to elucidate anti Acanthamoeba activity of specific AMPs. Acanthamoeba infection of the cornea is a serious and sight threatening condition with not licensed drug available for its treatment. Dilute disinfectant agents such as PHMB and chlorhexidine [38] are employed in a non-specific manner. The potential of using AMPs singly or in combination to combat this infection is a promising avenue for further exploration. 


\section{Acknowledgement:}

We thank Dr. Ilene Gipson, Schepens Eye Research Institute, for HCLE cells. The work was supported by a grant from the Royal Blind Asylum and School, The Royal College of Surgeons, Edinburgh (HSD) and by National Institutes of Health Grants EY09349 (NP) and a challenge grant from Research to Prevent Blindness to New England Eye Centre (NP).

\section{Copyright licence statement}

The Corresponding Author has the right to grant on behalf of all authors and does grant on behalf of all authors, an exclusive licence (or non-exclusive for government employees) on a worldwide basis to the BMJ Publishing Group Ltd and its Licensees to permit this article (if accepted) to be published in BJO editions and any other BMJPGL products and sub licences such use and exploit all subsidiary rights, as set out in our licence (http://bjo.bmj.com/ifora/licence.pdf)

\section{References}

1 Knop E, Knop N. Anatomy and immunology of the ocular surface. Chem Immunol Allergy. 2007;92:36-49.

2 Gordon YJ, Romanowski EG, McDermott AM. A review of antimicrobial peptides and their therapeutic potential as anti-infective drugs. Curr Eye Res. 2005;30:505-15.

3 Sang $\mathrm{Y}$, Blecha $\mathrm{F}$. Antimicrobial peptides and bacteriocins: alternatives to traditional antibiotics. Anim Health Res Rev. 2008;9:227-35.

4 Mclntosh RS, Cade JE, Al-Abed M, et al. The spectrum of antimicrobial peptide expression at the ocular surface. Invest Ophthalmol Vis Sci. 2005;46:137985.

$5 \quad$ Cordingley JS, Wills RA, Villemez CL. Osmolarity is an independent trigger of Acanthamoeba castellanii differentiation. J Cell Biochem. 1996;61:167-71.

6 Jaison PL, Cao Z, Panjwani N. Binding of Acanthamoeba to [corrected] mannose-glycoproteins of corneal epithelium: effect of injury. Curr Eye Res. 1998; 17:770-6.

7 Por YM, Mehta JS, Chua JL, et al. Acanthamoeba keratitis associated with contact lens wear in Singapore. Am J Ophthalmol. 2009;148:7-12 e2. 
8 Joslin CE, Tu EY, McMahon TT, et al. Epidemiological characteristics of a Chicago-area Acanthamoeba keratitis outbreak. Am J Ophthalmol. 2006;142:212-7.

9 Yang Z, Cao Z, Panjwani N. Pathogenesis of Acanthamoeba keratitis: carbohydrate-mediated host-parasite interactions. Infect Immun. 1997;65:439-45.

10 Hurt M, Niederkorn J, Alizadeh $\mathrm{H}$. Effects of mannose on Acanthamoeba castellanii proliferation and cytolytic ability to corneal epithelial cells. Invest Ophthalmol Vis Sci. 2003;44:3424-31.

11 Cao Z, Jefferson DM, Panjwani N. Role of carbohydrate-mediated adherence in cytopathogenic mechanisms of Acanthamoeba. J Biol Chem. 1998;273:15838-45.

12 Clarke DW, Alizadeh H, Niederkorn JY. Intracorneal instillation of latex beads induces macrophage-dependent protection against Acanthamoeba keratitis. Invest Ophthalmol Vis Sci. 2006;47:4917-25.

13 Mitra MM, Alizadeh H, Gerard RD, Niederkorn JY. Characterization of a plasminogen activator produced by Acanthamoeba castellanii. Mol Biochem Parasitol. 1995;73:157-64.

14 Mitro K, Bhagavathiammai A, Zhou OM, et al. Partial characterization of the proteolytic secretions of Acanthamoeba polyphaga. Exp Parasitol. 1994;78:377-85.

15 Gipson IK, Spurr-Michaud S, Argueso P, et al. Mucin gene expression in immortalized human corneal-limbal and conjunctival epithelial cell lines. Invest Ophthalmol Vis Sci. 2003;44:2496-506.

16 Robertson DM, Li L, Fisher S, et al. Characterization of growth and differentiation in a telomerase-immortalized human corneal epithelial cell line. Invest Ophthalmol Vis Sci. 2005;46:470-8.

17 Castro-Munozledo F. Corneal epithelial cell cultures as a tool for research, drug screening and testing. Exp Eye Res. 2008;86:459-69.

18 Jensen T, Barnes WG, Meyers D. Axenic cultivation of large populations of Acanthamoeba castellanii (JBM). J Parasitol. 1970;56:904-6.

19 Ueta M, Kinoshita S. Innate immunity of the ocular surface. Brain Res Bull. 2009.

20 Hazlett LD. Corneal response to Pseudomonas aeruginosa infection. Prog Retin Eye Res. 2004;23:1-30.

21 Huang LC, Jean D, Proske RJ, et al. Ocular surface expression and in vitro activity of antimicrobial peptides. Curr Eye Res. 2007;32:595-609.

22 McDermott AM. The role of antimicrobial peptides at the ocular surface. Ophthalmic Res. 2009;41:60-75.

23 Schuster FL, Jacob LS. Effects of magainins on ameba and cyst stages of Acanthamoeba polyphaga. Antimicrob Agents Chemother. 1992;36:1263-71.

24 Feldman ST, Speaker M, Cleveland P. Effect of magainins on Acanthamoeba castellanii. Rev Infect Dis. 1991;13 Suppl 5:S439.

25 Sacramento RS, Martins RM, Miranda A, et al. Differential effects of alphahelical and beta-hairpin antimicrobial peptides against Acanthamoeba castellanii. Parasitology. 2009;136:813-21.

26 Harder J, Bartels J, Christophers E, Schroder JM. Isolation and characterization of human beta -defensin-3, a novel human inducible peptide antibiotic. J Biol Chem. 2001;276:5707-13.

27 Pigeon C, llyin G, Courselaud B, et al. A new mouse liver-specific gene, encoding a protein homologous to human antimicrobial peptide hepcidin, is overexpressed during iron overload. J Biol Chem. 2001;276:7811-9. 
28 Ganz T. Hepcidin--a peptide hormone at the interface of innate immunity and iron metabolism. Curr Top Microbiol Immunol. 2006;306:183-98.

29 Flanagan JL, Willcox MD. Role of lactoferrin in the tear film. Biochimie. 2009;91:35-43.

30 Krause A, Neitz S, Magert HJ, et al. LEAP-1, a novel highly disulfide-bonded human peptide, exhibits antimicrobial activity. FEBS Lett. 2000;480:147-50.

31 Wang X, Zhang Z, Louboutin JP, et al. Airway epithelia regulate expression of human beta-defensin 2 through Toll-like receptor 2. FASEB J. 2003;17:1727-9.

32 Abedin A, Mohammed I, Hopkinson A, Dua HS. A novel antimicrobial peptide on the ocular surface shows decreased expression in inflammation and infection. Invest Ophthalmol Vis Sci. 2008;49:28-33.

33 Gordon YJ, Huang LC, Romanowski EG, et al. Human cathelicidin (LL-37), a multifunctional peptide, is expressed by ocular surface epithelia and has potent antibacterial and antiviral activity. Curr Eye Res. 2005;30:385-94.

34 Maltseva IA, Fleiszig SM, Evans DJ, et al. Exposure of human corneal epithelial cells to contact lenses in vitro suppresses the upregulation of human betadefensin-2 in response to antigens of Pseudomonas aeruginosa. Exp Eye Res. 2007;85:142-53.

35 Townes $\mathrm{CL}$, Michailidis $\mathrm{G}$, Hall $\mathrm{J}$. The interaction of the antimicrobial peptide CLEAP-2 and the bacterial membrane. Biochem Biophys Res Commun. 2009;387:500-3.

36 Hocquellet A, Odaert B, Cabanne C, et al. Structure-activity relationship of human liver-expressed antimicrobial peptide 2. Peptides. 2009.

37 Harder J, Schroder JM. RNase 7, a novel innate immune defense antimicrobial protein of healthy human skin. J Biol Chem. 2002;277:46779-84.

38 Dart JK, Saw VP, Kilvington S. Acanthamoeba keratitis: diagnosis and treatment update 2009. Am J Ophthalmol. 2009;148:487-99 e2. 
Figure legends

Figure1- The AMPs gene expression in HCLE stimulated with AC $\left({ }^{*}=\mathrm{P}\right.$ value is less than $0.05,{ }^{* *}=\mathrm{P}$ value is less than $0.01,{ }^{* * *}=\mathrm{P}$ value is less than $0.001)$ 
hBD1 gene expression in HCLE stimulated with AC

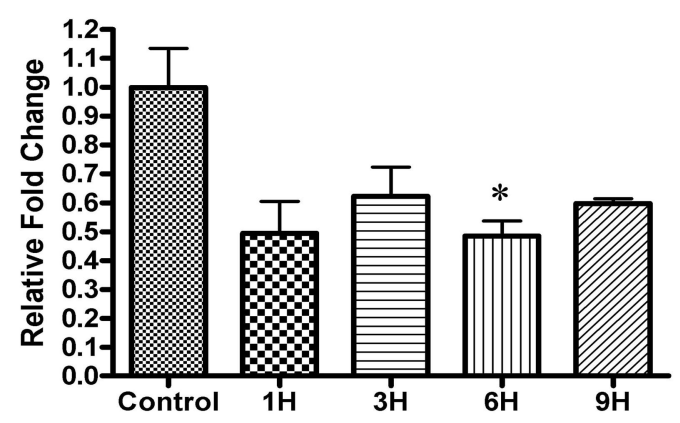

hBD3 gene expression in HCLE stimulated with AC

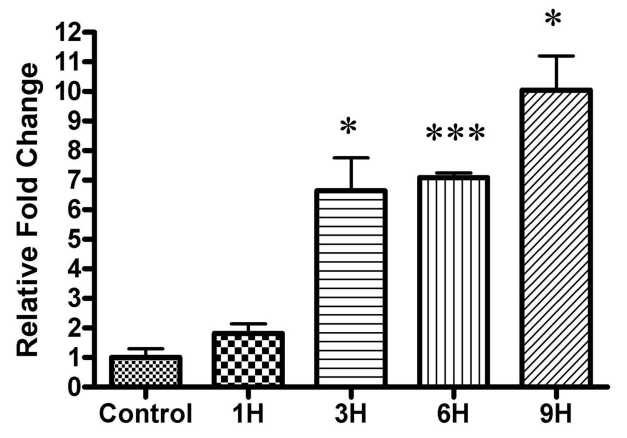

LL37 gene expression in HCLE stimulated with AC

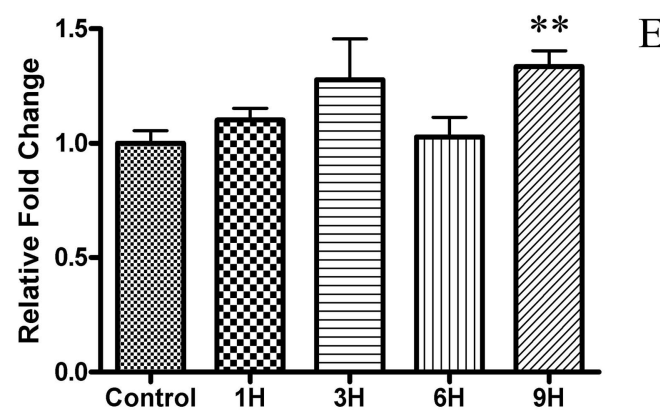

hBD2 gene expression in HCLE stimulated with AC

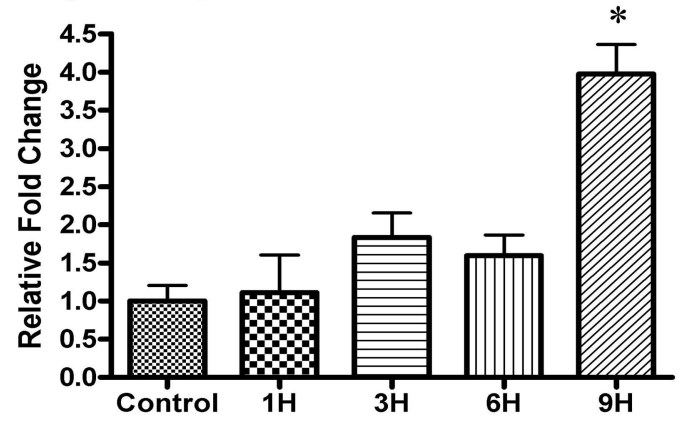

$\mathrm{B}$

DEFB109 gene expression in HCLE stimulated with AC

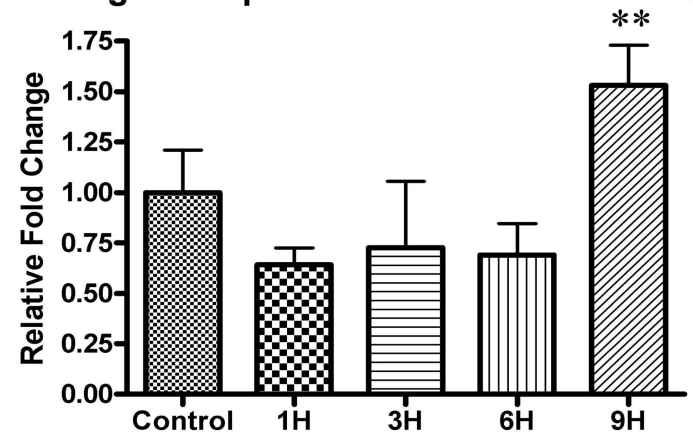

D

LEAP1 gene expression in HCLE stimulated with AC

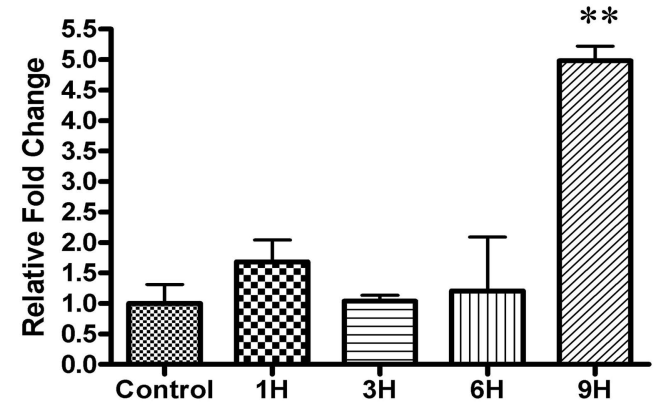

RNase7 gene expression in HCLE stimulated with PA

LEAP2 gene expression in HCLE stimulated with AC
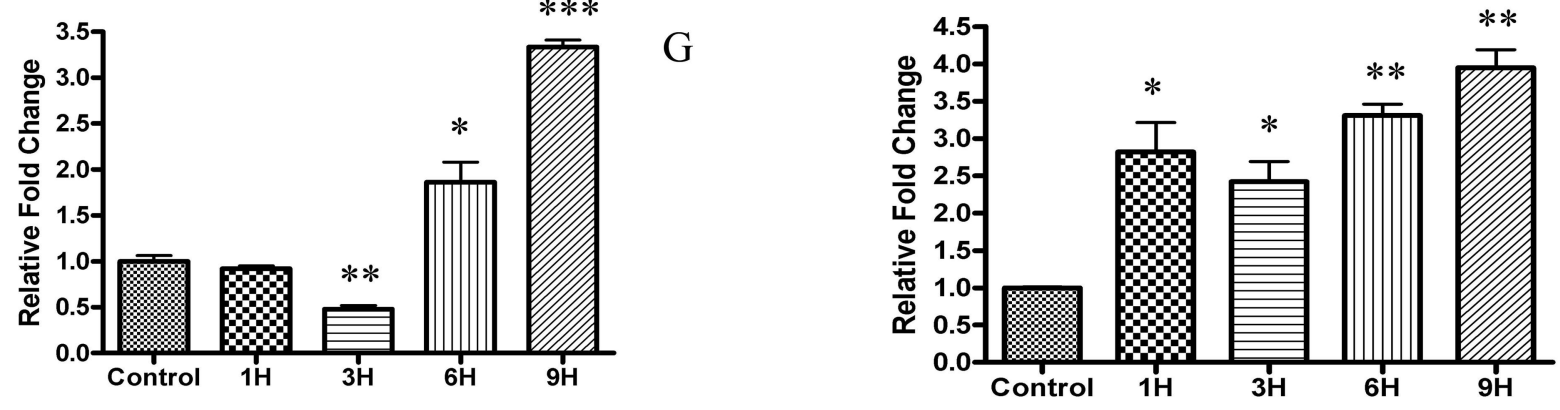

$\mathrm{H}$ 